\title{
ResonantSonic Drilling
}

\section{INNOVATIVE TECHNOLOGY SUMMARY REPORT}

demonstrated at

U.S. Department of Energy

Hanford Site and Sandia

National Laboratory

Richland, WA and Albuquerque, NM

prepared for

U.S. Department of Energy

Office of Environmental Management

Office of Technology Development

April 1995 


\section{DISCLAIMER}

This report was prepared as an account of work sponsored by an agency of the United States Government. Neither the United States Government nor any agency thereof, nor any of their employees, make any warranty, express or implied, or assumes any legal liability or responsibility for the accuracy, completeness, or usefulness of any information, apparatus, product, or process disclosed, or represents that its use would not infringe privately owned rights. Reference herein to any specific commercial product, process, or service by trade name, trademark, manufacturer, or otherwise does not necessarily constitute or imply its endorsement, recommendation, or favoring by the United States Government or any agency thereof. The views and opinions of authors expressed herein do not necessarily state or reflect those of the United States Government or any agency thereof. 


\section{DISCLAIMER}

Portions of this document may be illegible in electronic image products. Images are produced from the best available original document. 


\section{TABLE OF CONTENTS}

1 SUMMARY

page 1

2 TECHNOLOGY DESCRIPTION

page 3

3 PERFORMANCE

page 6

4 TECHNOLOGY APPLICABILITY \& ALTERNATIVES

page 10

$5 \cos T$

page 11

6 REGULATORY/POLICY ISSUES

page 13

7 LESSONS LEARNED

page 14

APPENDICES

A Demonstration Site Characteristics

B References 


\section{SECTION 1}

\section{SUMMARY}

\section{Technology Description}

ResonantSonic ${ }^{S M}$ drilling has been demonstrated and deployed as an innovative tool to access the subsurface for installation of monitoring and/or remediation wells and for collection of subsurface materials for environmental restoration applications. The technology has been developed by industry with assistance from the U.S. Department of Energy (DOE) Office of Technology Development to ensure it meets the needs of the environmental restoration market.

The ResonantSonic drilling technology:

- can provide excellent quality, relatively undisturbed, continuous core samples that can be used for contaminated site characterization and for subsurface engineering design;

- uses no drilling fluids and minimizes generation of waste associated with the drilling operations (no cuttings);

- provides an alternative drilling method that at some locations is more cost effective than the baseline technology (e.g., at Hanford it can augment or replace cable tool drilling);

- can be used to drill slant holes;

- can be safer because worker exposure is minimized, because drilling is faster and waste generated is minimized; and

- can be used for retrieving core materials from the subsurface (i.e., sample collection), for installation of monitoring wells, and for providing subsurface access for collection of ground water samples.

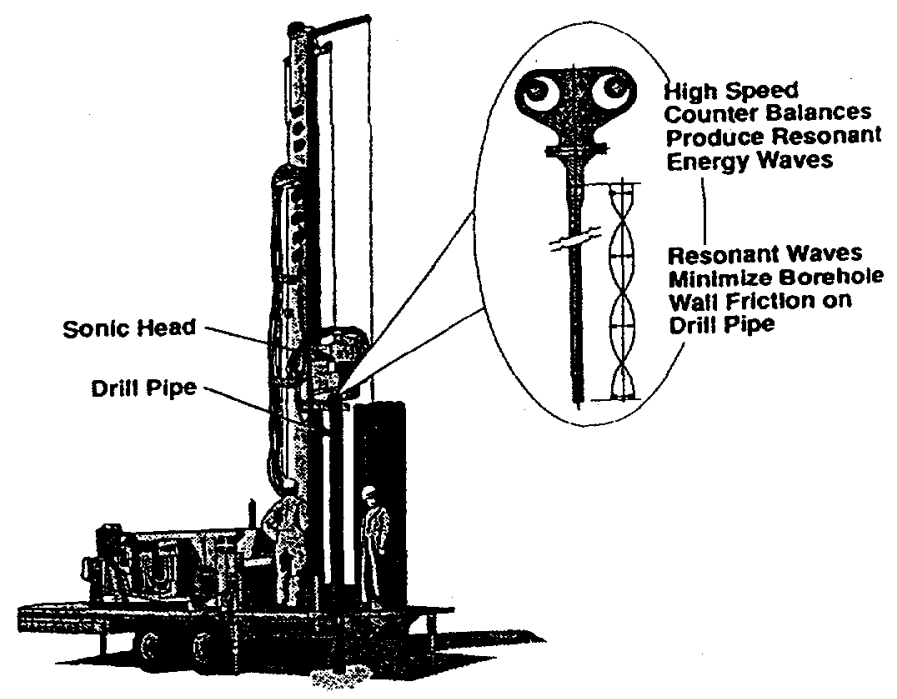

- The ResonantSonic drilling system consists of two components: the drill head and the resonator (i.e., the drill pipe or rod).

- Three different mechanisms allow the bit to penetrate the formation: displacement, shearing, and fracturing. At any particular site, the mechanism is dependent upon the soil medium being drilled.

- ResonantSonic drilling has been used at many geologically different sites ranging from unconsolidated gravel-rich material to sandstone/shale sequences to clay-rich glacial till sites.

- Continuous cores have been obtained at depths as great as 550 feet.

- Drilling rates range up to 260 feet per day.

- Costs range from $\$ 70$ to $\$ 300$ per foot depending upon the drilling system used, the drilling approach, the site geology, etc.

(SMI "Registered Service Mark of Water Development Corporation" 


\section{Technology Status}

- The original patent was developed by Albert Bodine in the early 1960s; the technology was used for pile driving and mineral exploration, especially in Canada. Several U.S. companies have purchased the Canadian equipment and licensed any existing patents to pursue a new market for this drilling technology.

- Water Development Corporation of California teamed with the Department of Energy via a Cooperative Research and Development Agreement (CRADA) to advance the application of this technology to the environmental business. The joint industry-government partnership mission was to develop and demonstrate improvements to the ResonantSonic technology so that it could be applied cost effectively to environmental restoration sites with special focus on difficult drilling sites such as the DOE Hanford Site.

- Field demonstrations of the ResonantSonic drilling technology were conducted at the DOE Hanford Site and at Sandia National Laboratory from 1991 through 1994. Refinements to the drilling system concentrated on improving th a reliability of the equipment, developing new bit designs, pursuing automated tool handling and decontamination systems, and demonstrating angle drilling capabilities.

- Additional demonstrations have been conducted at the DOE Pantex Site in Amarillo, Texas and at a number of DOD military bases. Further, the technology has been implemented at the DOE Rocky Flats Site, at the Idaho National Engineering Laboratory, and at a number of private locations in California.

- Key results of the public-privale partnership technology development program include the following:

- In the initial demonstration at Hanford, penetration rates were twice that of the baseline technology; later results showed improvements as high as three to four times that of the baseline.

- Equipment refinements included a new sonic head design, new drill pipe designs, an automated pipe handling system, and an extended-length split-tube sampler.

- A method to maintain core temperatures, below 90 degrees Fahrenheit, to assure quality core recovery for VOC analysis was developed and tested.

- A new rig that has multiple drilling technology capabilities (sonic, air rotary casing hammer, cable tool, percussion, and rotary) was designed and manufactured. The advantages of such a system include the ability to mix and match drilling technologies to the required objectives at each specific drilling location.

- Angle-drilled wells have been installed at both Sandia National Laboratory and Hanford.

- The technology is commercially available. The number of companies that can provide such services is quite limited, however.

\section{Contacts}

\section{Technical}

Don Moak/Greg McLellan (p.i.), Westinghouse Hanford Company, (509) 373-7219/373-7539

Jack Wise, Sandia National Laboratories, (505) 844-6359

Jeffrey Barrow, Water Development Corporation, (916) 662-2829

\section{Management}

David Biancosino, DOE EM50 Program Manager, (301) 903-7961

Jim Wright, DOE Plumes Focus Area Manager, (803) 725-5608

\section{Licensing Information}

Jeffrey Barrow, Water Development Corporation, (916) 662-2829 


\section{TECHNOLOGY DESCRIPTION}

Overall Drilling Rig Schematic

\section{ResonantSonic"m Drilling Method}

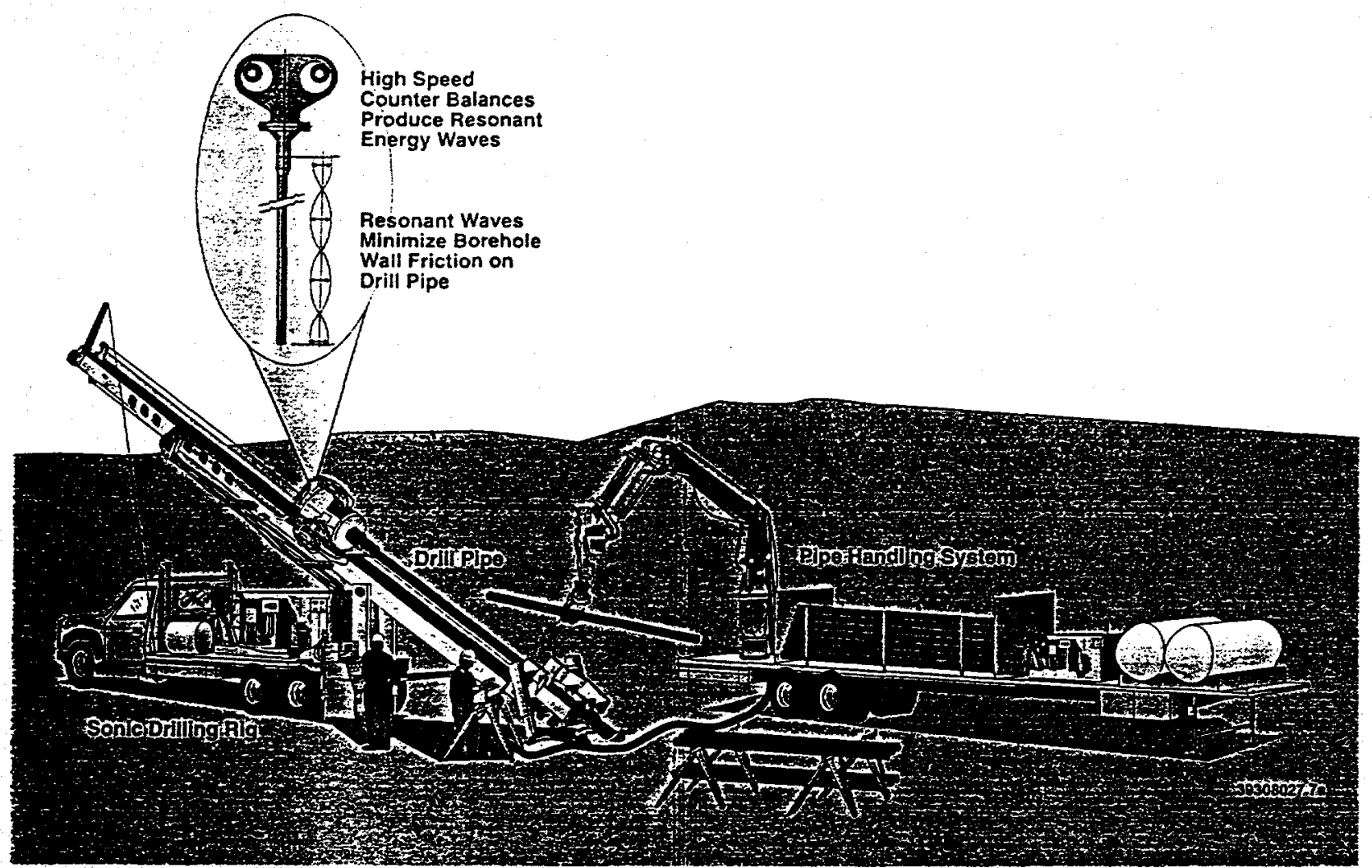

- The ResonantSonic drilling rig uses a combination of mechanically generated vibrations and limited rotary power to penetrate the soil.

- The oscillator or drill head consists of two counter rotating, out-of-balance rollers that cause the drill pipe to vibrate. The rollers are synchronized with each other to ensure that the vertical force component is transmitted downward along the drill pipe or core barrel.

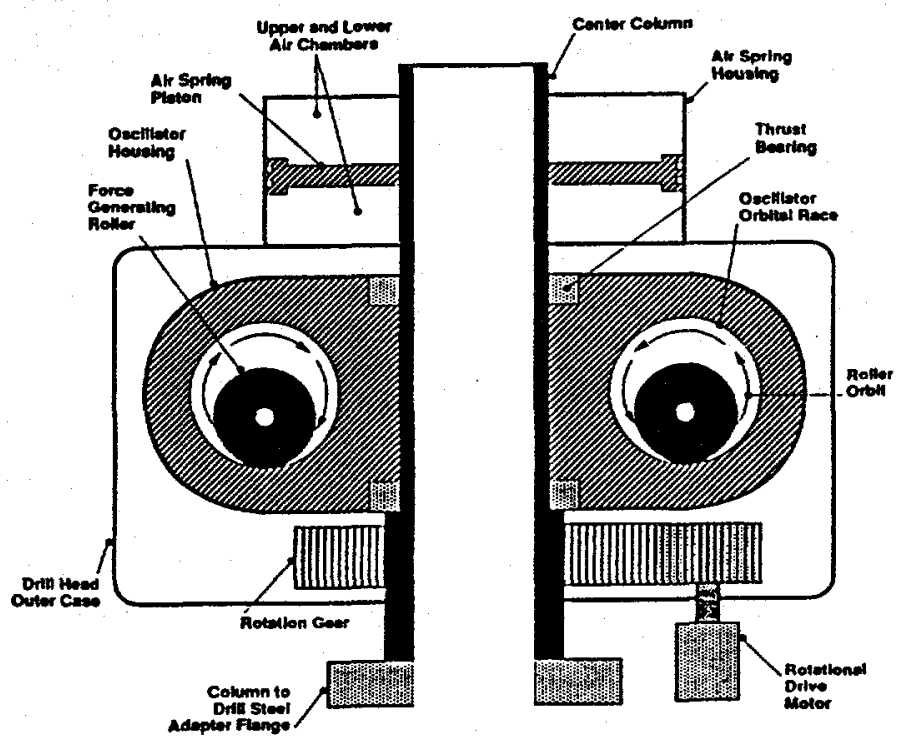


- The vibrations are isolated from the rig structure by the use of an air spring.

- Resonance occurs when the frequency of the vibrations is equal to the natural frequency of the drill pipe. In resonance, forces generated by the oscillator head can build up in the pipe from 50,000 to 280,000 pounds. The resonance and weight of the drill pipe along with the downward thrust of the drill head permit penetration of the formation.

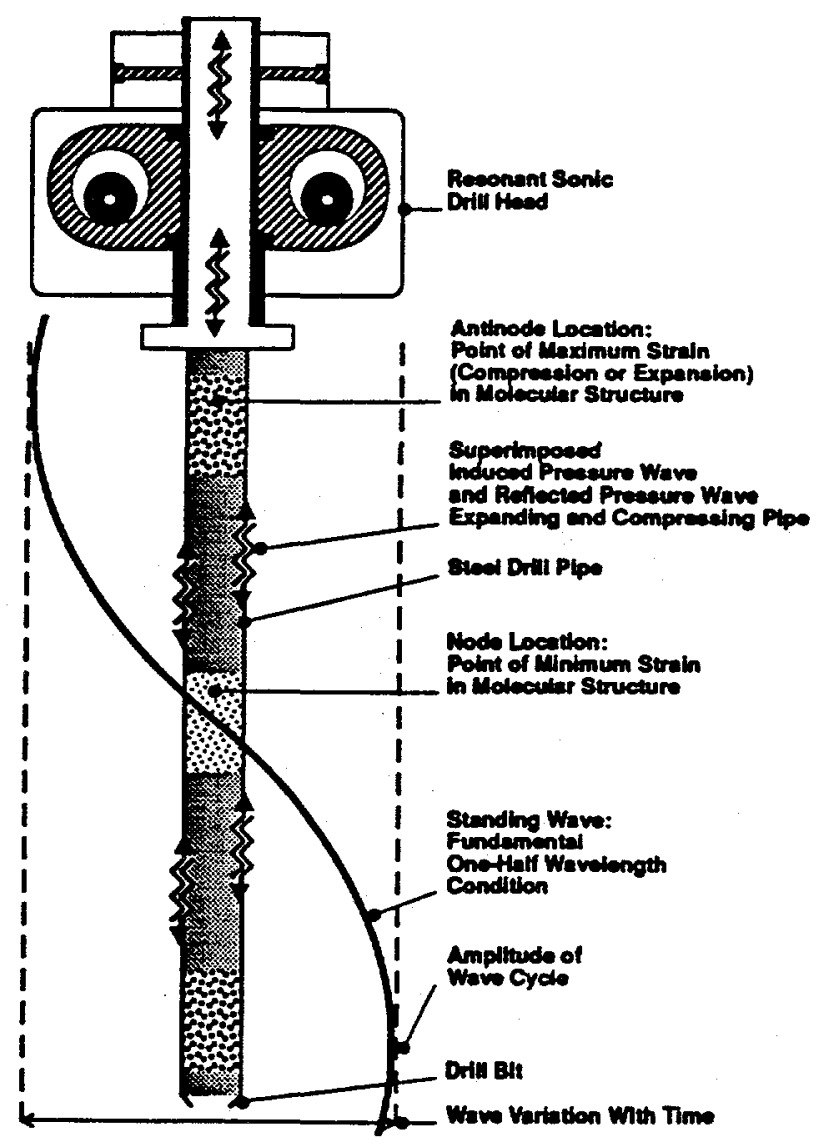

- The newly designed ResonantSonic drill head also has rotation capability up to 8,500 foot pounds of torque to assist with penetration of the formation.

- Vibrations generated in the drill string range from 0 to greater than $150 \mathrm{Hertz}$ and create up to 200,000 pounds of force. The drill pipe is advanced into the ground by weight applied hydraulically at the surface.

\section{System Configuration and Operation}

- There are two primary methods for retrieving core samples from the subsurface: the wireline method and the dual-rod method. Each method, of course, has advantages and disadvantages. The selection of a specific method must be tailored to the site-specific needs and conditions. The advantages and disadvantages of the two methods with a comparison to rotasonic drilling are discussed in Reference 5.

- The wireline method uses an open-face core bit threaded to the bottom of the drill pipe. An inner core barrel rests on the shoulder of the bit and is kept in place during drilling by a downhole latch assembly or heavy weight. After drilling has proceeded far enough that the barrel is filled, the wireline retrieval system is attached to the core barrel so that it can be removed without pulling the drill pipe out of the hole.

- The dual-rod system is similar to the wireline method, but the core barrel is attached to a small diameter steel inner rod, which then must be removed during core retrieval. This assures quality seating of the core barrel. Both drill rods can be resonated simultaneously or independently, depending upon formation conditions. Little if any rotation of the drill rods is used 
with this system. Neither the wireline nor the dual rod method requires addition of fluids to the subsurface. They both can be used with the ResonantSonic system.

- Borehole integrity is maintained by the drill pipe that remains in the ground as the core barrel is retrieved and as the hole is advanced. Typical drill pipe diameter is 4.5 inches outer diameter (OD). Larger-size drill pipe ranging from $65 / 8$ to 16 inch diameter can be used when telescoping pipe is required to seal a perched zone or confined aquifer or to make larger diameter monitoring or remediation wells.

- To install monitoring wells, the drill pipe acts as a temporary casing, inside of which the well materials can be placed for installation. It is quite easy to retrieve the temporary casing because it can be sonically vibrated to assist removal.

- Specifications of the six different drilling rigs used for the Hanford and Sandia demonstrations are shown below.

\begin{tabular}{|c|c|c|c|c|c|c|}
\hline Sonic drilling rig & $\begin{array}{l}\text { 15-year-old } \\
\text { rig used at } \\
\text { Hanford }\end{array}$ & $\begin{array}{l}\text { "Barber" } \\
\text { rig used at } \\
\text { Sandia }\end{array}$ & $\begin{array}{l}\text { "Dresser" } \\
\text { rig used at } \\
\text { Sandia }\end{array}$ & $\begin{array}{l}\text { "Angle" rig } \\
\text { used al } \\
\text { Sandia }\end{array}$ & $\begin{array}{l}\text { "RSD300" } \\
\text { rig used at } \\
\text { Hantord }\end{array}$ & $\begin{array}{l}\text { "RSD750' } \\
\text { planned at } \\
\text { Hantord }\end{array}$ \\
\hline Resonant frequency & $\begin{array}{c}0 \text { to } 150 \\
\text { Hertz }\end{array}$ & $\begin{array}{l}01015 \\
0 \text { Hertz }\end{array}$ & $\begin{array}{l}0 \text { to } 150 \\
\text { Hertz }\end{array}$ & $\begin{array}{l}0 \text { to } 15 \\
0 \text { Hertz }\end{array}$ & $\begin{array}{c}0 \text { to } 150 \\
\text { Hertz }\end{array}$ & $\begin{array}{l}0 \text { to } 15 \\
0 \text { Hertz }\end{array}$ \\
\hline Rig Power & $250 \mathrm{Hp}$ & $250 \mathrm{Hp}$ & $250 \mathrm{Hp}$ & $250 \mathrm{Hp}$ & $300 \mathrm{Hp}$ & $1200 \mathrm{Hp}$ \\
\hline $\begin{array}{l}\text { Maximum force } \\
\text { generated by the drill } \\
\text { head. }\end{array}$ & $50,000 \mathrm{lbs}$. & $50,000 \mathrm{lbs}$. & 50,000 lbs. & $50,000 \mathrm{lbs}$ & 100,000 lbs. & 200,000 lbs. \\
\hline $\begin{array}{l}\text { Maximum force } \\
\text { transmitted due to } \\
\text { hydraulic thrust alone }\end{array}$ & 10,000 lbs. & 15,000 llbs & $15,000 \mathrm{lbs}$ & $15,000 \mathrm{lbs}$. & 30,000 lbs. & $90,000 \mathrm{lbs}$. \\
\hline $\begin{array}{l}\text { Hole diiameter that } \\
\text { can be drilled }\end{array}$ & up to 7 in. & up to $65 / 8$ in. & up to $65 / 8$ in. & up to $65 / 8$ in. & up to $103 / 4 \mathrm{in}$. & up to 16 in. \\
\hline
\end{tabular}

\section{Operational Requirements}

- ResonantSonic drilling requires one driller and one helper as a minimum for operation. Drilling at hazardous waste sites, of course, requires additional personnel. At a DOE hazardous waste site the field team could include a field team leader, a geologist, a site safety officer, a sampling scientist, a health physics technician, and two sampling technicians. The large number of personnel required significantly affects the cost of the drilling operation and maximizes the cost differential between different drilling technologies, because one technology is faster than the other.

- The ResonantSonic drill required about 2.5 hours of preventive maintenance per week during the first demonstration and less during subsequent demonstrations.

- The Los Alamos National Laboratory (LANL) cost estimate uses a figure of $\$ 20,000$ per year cost for preventive maintenance.

- Stress on the drill pipe produced during resonance causes internal damages. Magnetic scanning of the drill pipe (magnafluxing) can be performed routinely to reveal microfractures. However, microfractures are not readily identified in all cases because the initial failure points occur within the body of the pipe. 


\section{SECTION 3}

\section{PERFORMANCE}

\section{Demonstration Overview}

First demonstration with Harrison Western, Inc., 1991-1992

- The first demonstration of ResonantSonic drilling technology, which took place in 1991 at Hanford, was conducted jointly by DOE EM40 and EM50 to determine whether sonic drilling is a cost-effective alternative to the currently used cable-tool system for drilling and sampling at hazardous and radioactive waste sites at Hanford. Other requirements for the system include protection of human health and the environment and compliance with state and federal regulations.

\section{CRADA demonstrations with Water Development Corporation, 1993-1994}

- Objectives of the 1993 demonstrations included the following:

- Demonstrate the efficiency and reliability of the sonic drill head in penetrating variable geologic conditions.

- Demonstrate angle drilling capabilities and determine areas for improvements.

- Develop and install an instrumentation system to electronically record the resonant drilling process.

- Correlate recorded drilling measurements with geology.

- Test and evaluate sampling equipment and sample handling methods for both vertical and angle drilling.

- Demonstrate that ResonantSonic drilling can meet safety standards and compliance with state regulations for well completions.

- Demonstrate the ability to maintain contamination control and minimize generated waste.

- Demonstrate ability to obtain high quality samples (including maintenance of an acceptable bit face temperature) and drill to required depths at required diameters.

- Evaluate cost effectiveness of ResonantSonic versus cable tool drilling.

- Determine the radial distance from the borehole of vibrations generated during drilling.

- Demonstrate, evaluate, and select a preferred sonic drill rod.

\section{Drilling Performance}

\section{First Hanford Demonstration, 1991-1992}

- The first demonstration at Hanford utilized a fifteen-year-old rig (Hawker-Siddely drill owned by Harrison Western Drilling, Inc.). This demonstration was plagued with high percentages of downtime due mostly to head and drill string failures related to the age of the equipment. This first demonstration laid the groundwork for future development work by demonstrating the technology's potential while demonstrating the need for more development.

- The ResonantSonic drill averaged 23.9 feet per day as compared with the average rate of 12.6 feet per day for cable tool (downtime excluded for both technologies). Including downtime, sonic averaged 8.9 feet per day and cable tool averaged 8.1 feet per day on a comparison of ten sonic drilled boreholes and 11 cable tool drilled boreholes. Average cable tool drilling rates at Hanford in 1991 ranged from 6.4 to 9.5 feet per day.

- Eight ground water monitoring wells, one ground water monitoring/extraction well, and two vadose zone characterization boreholes were completed during the demonstration. The borings ranged in depth from 30 to 227 feet and were located in several areas at the Hanford Site (100-D, 300, 3000, 200 East, and 200 West).

- The ResonantSonic drilling system provided intact lithologic samples that are not usually retrieved with the cable tool system. Sample quality for the sonic boreholes was at least equal to that of cable tool in sand and silt formations and was greater in hard formations unless large cobbles were encountered.

- The ResonantSonic drilling system protected human health and the environment by minimizing waste generation and easily containing cuttings.

- The ResonantSonic drilling method offers several advantages for well completion: temporary casing can be rotated and placed in resonance to prevent bridging of the completion material (this results in faster installation of the annular seal); rig hydraulics can be used to unscrew and handle the temporary casing; the same crew can be used for well installation (no additional crew mobilization is required). 


\section{Dr. Bill Schutte of the DOE Office of Technology Development watches the Hanford ResonantSonic drilling demonstration with Mr. Greg McLellan, principal investigator, Westinghouse Hanford Company.}

\section{Hanford CRADA Demonstrations, 1993-1994}

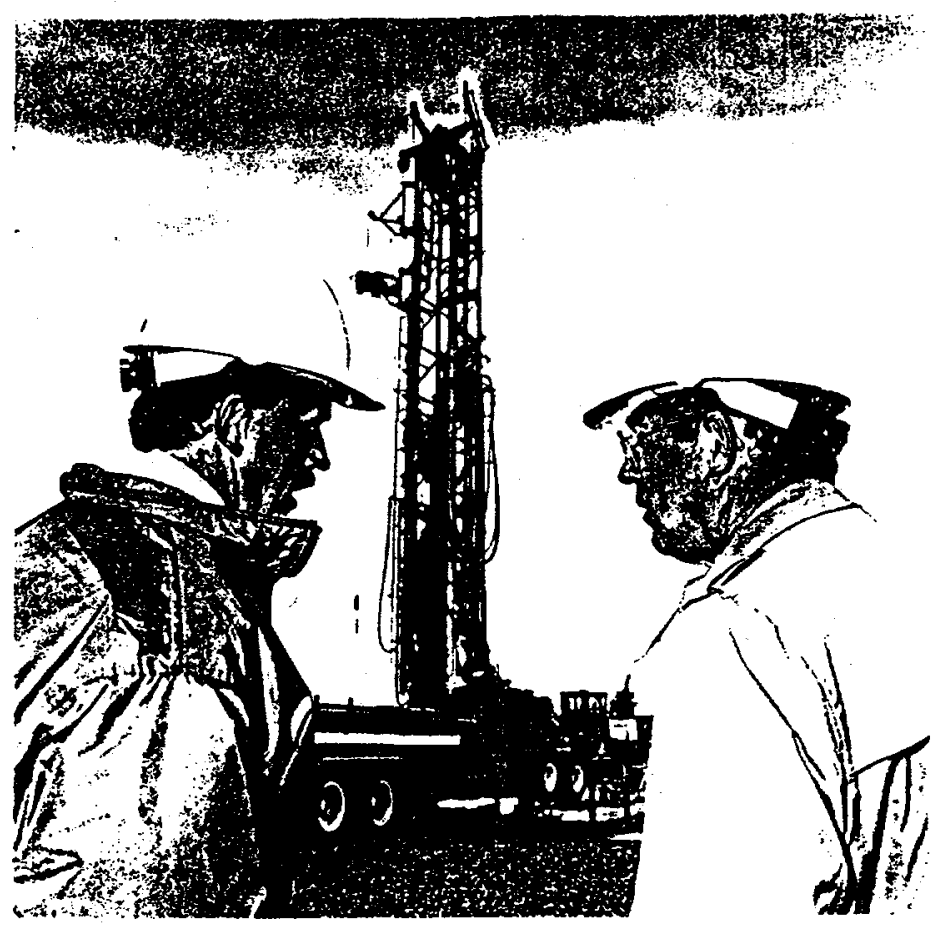

- During the first phase of this demonstration program, five boreholes were drilled, four of which were at 45 degree angles. The two deepest wells reached total lengths of 164 and 172 feet. Drilling rates averaged six feet per hour.

- Sampling equipment and methods investigated included core tray, split tube samplers, and core barrel liners.

- Concerns about sampling of core for analysis of VOCs due to heating of the core were examined and a new methodology was developed to minimize temperature elevation in the core. During the first demonstration at Sandia and Hanford, core samples

\section{An example of unsonsolidated core removed using the ResonantSonic system.}

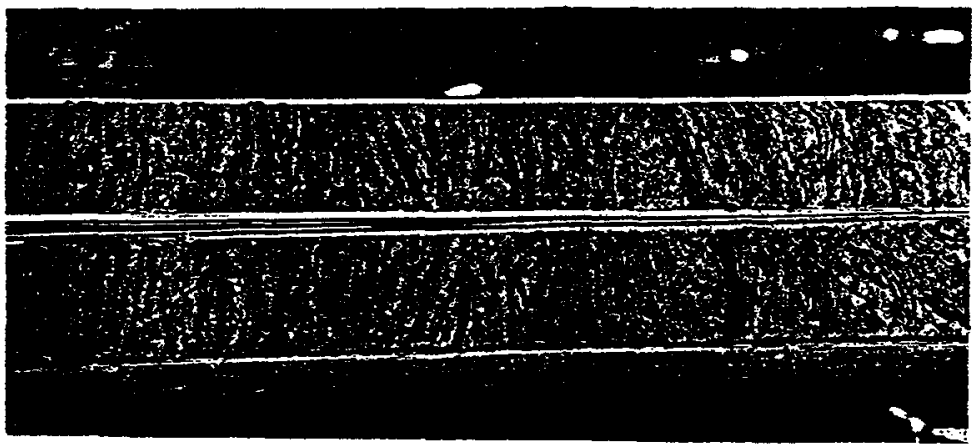

were heated to temperatures unacceptable for chemical sampling.

- An extended-length split-tube sampler was designed to be driven ahead of the drill string and filled to only $75 \%$ of its length to obtain samples for chemical analysis.

- Other improvements include reductions in drilling frequencies and rotation rate as a result of real-time temperature monitoring, lining of the samplers with low thermal conductivity materials (Lexan), and pre-chilling the samplers with dry ice in special coolers. 
- The second phase included installation of a 45-degree-angle vapor-extraction borehole to a measured depth of 168 feet (118 feet vertical depth) with 3-inch stainless steel casing at a hazardous waste site under a parking lot in the 200 West Area.

- New developments in the drilling system included the use of Lexan liners to collect superior quality core, core temperatures held to under 90 degrees Fahrenheit, and the use of a robotic arm to handle the drill pipe.

- Downtime was less than five percent.

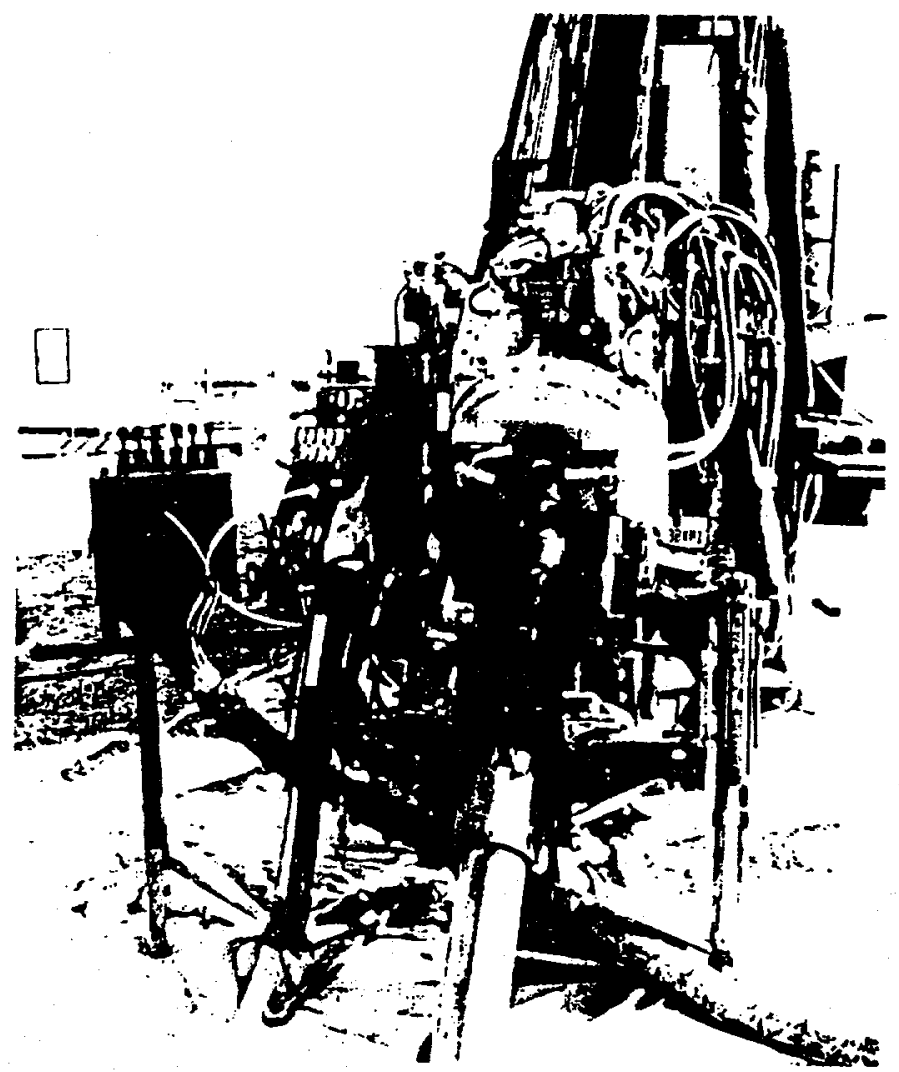

- Later phases of the CRADA demonstrations included drilling with larger-diameter drill pipe (up to 20 inches) and installation of deep wells (310 feet) with 4-inch stainless steel pipe.

- Drill pipe analysis showed that eddy currents could detect abnormal electric or magnetic features in the threaded fastener region, where pipe failure occurs most often. Failure analysis of the pipe itself demonstrated a difference between pipe that was threaded directly and in pipe that utilized threaded tool pieces.

\section{DOE Sandia National Laboratory Demonstrations}

- In 1993 three different ResonantSonic rigs were demonstrated at Sandia. All three were rigs newer than that used at the 19911992 Hanford demonstration.

- Technological advances in both the drill head and drill string resulted in much less downtime (averaged 5-10\%) during the Sandia demonstrations.

- Two 4-inch PVC slant wells (15 degrees from horizontal) were installed beneath the Chemical Waste Landfill to a depth of 150 feet.

- During the drilling operations, dynamic drilling measurements were made to obtain information on pipe integrity. A new instrumented subassembly was designed and manufactured to be used for this demonstration. This was the first step toward development of diagnostic capabilities to enhance drilling performance through optimized control and improved hardware design.

- The boreholes did not deviate off linearity by more than one-half degree over the full length of the wells. 


\section{DOE Pantex Demonstration 1994}

- Four continuous core boreholes were completed to average depths of 290 feet, where a continuous perched water interval overlying the Ogalalla Aquifer exists.

- Depth-discrete ground water sampling using the HydroPunch and geophysical logging were combined with the ResonantSonic drilling method to maximize the amount of information obtained from each of the boreholes.

- The amount of waste generated was $2 \%$ of that normally obtained using the baseline Pantex technology. 


\section{Marketplace Opportunities}

- The optimum application of ResonantSonic drilling technology will be at sites where:

1) high-quality core materials are required; the ResonantSonic drilling system provides intact core samples that demonstrate detailed lithological parameters such as thin layers (such as clays and chemical precipitates) and fragile structures (depositional and fossiliferous features) that are normally not observed in samples collected by other drilling methods;

2) where there is a requirement to minimize the amount of hazardous waste generated; Land Disposal Restrictions (LDR) now require containment, storage, and ultimate treatment of investigative-derived wastes such as drill cuttings and drilling fluids;

3) when regulators prefer the use of a drilling technology that does not add fluids to the subsurface; at many sites there may be concems about the migration of contaminants being exacerbated by the addition of drilling fluids; and

4) lithology is not conducive to conventional technology (e.g., karst).

\section{Alternative Technologies}

\section{Rotasonic}

- This technology, most closely related to the resonant sonic method, is a modification of the original Albert Bodine patent and is presently commercially available from a few companies in the United States.

- Rotasonic drilling uses a core barrel attached to a drill rod as an inner casing. The core barrel is advanced sonically until it has been filled. The core barrel is then overwashed with a fluidized outer rotational casing, which provides hole stability while the inner drill string is pulled to retrieve the core. Disadvantages of this method include the requirement for addition of water to the subsurface for advancing casing and the time required to drill two holes, the cored section and the washover. One advantage is more rapid drilling penetration rates due to the fluidized condition of the borehole.

- The major disadvantage to this system, only at certain sites, is the requirement for the addition of water to the subsurface.

- Advantages that may offset this disadvantage include greatly increased penetration rates, much less stress on the tools and the overall system, and reduction of heat generated.

- Drilling rates with the rotasonic technology can be as high as 160 feet per day but of course are highly dependent upon the type of lithology being drilled.

- Depth is currently limited to 300 to 400 feet and the size of casings to be advanced is limited to eight inches.

- Rotasonic technology has been demonstrated for environmental applications at the DOE Savannah River Site and Oak Ridge National Laboratory and will soon be implemented at the Fernald Site in Ohio. It has been utilized extensively at a number of other sites including Wright-Patterson Air Force Base.

\section{Competitive Technologies}

- Competitive drilling technologies, including the baseline typically used within certain areas of the United States, consist of the following: cable tool, hollow-stem auger, mud rotary, air rotary, dual-wall percussion hammer, dual-tube reverse circulation, and air rotary casing hammer.

- Some of these technologies require the addition of fluids to the subsurface, and many generate significant quantities of hazardous waste when used at environmental restoration sites.

- A more complete discussion of drilling technologies can be found in reference 5. Costs for each of the technologies are very site dependent. 


\section{SECTION 5}

\section{COST}

\section{Introduction}

Information in this section was prepared from data provided by the VOCs in Arid Soils Integrated Demonstration at the DOE Hanford Site and the Mixed Waste Landfill Integrated Demonstration at the DOE Sandia National Laboratory to the Los Alamos National Laboratory (LANL), tasked to perform technology cost analyses as an independent team for the DOE Office of Environmental Management Office of Technology Development (EM-50).

-The LANL cost analysis was not meant to involve comprehensive cost estimation for borehole drilling and/or well completion.

Thus, the final cost-per-foot numbers would not be expected to match actual contract rates.

- The data provided to Los Alamos for the Hanford demonstrations relied solely on work performed in 1991-1992. This cost information was based on using 15-year-old drilling equipment and did not incorporate any of the advancements developed as a result of the technology development CRADA program in place over the last few years. Cost information from the later demonstrations will be available in the near future. Preliminary information suggests that costs have been significantly reduced, by as much as a factor of three.

-The testing at Sandia involved drilling of smaller diameter holes. Costs at Hanford are higher for this and a number of other reasons. Costs cannot be correlated from site to site.

\section{Cost Comparisons}

Two conventional technologies will be used as baselines for comparison to ResonantSonic Drilling. At Hanford, cable-tool drilling is considered to be the baseline for this cost analysis. At Sandia mud rotary drilling was considered the baseline for the cost analysis. A side-by-side comparison of three technologies was performed based on the following assumptions:

-The scenario assumed a hypothetical 150 -foot well to be drilled in three environments: 1) a clean environmental site, containing no hazardous or radioactive material, 2) a hazardous environmental site (EPA listed), and 3) a mixed-waste site, containing both hazardous and radioactive waste.

-Two separate soil conditions were considered: 1) regular drilling, which refers to the somewhat easier drilling of unconsolidated formations, and 2) difficult drilling, which refers to cobble/boulder/consolidated and clay layers where greater resistance to drill advance is encountered.

- Capital costs were included as rig rental to produce an overall drilling rate on a cost-per-foot basis. The table below presents a dollars/foot comparison of the three methods of drilling.

\section{Capital and Operating Costs}

Capital costs for the three systems are all within the same order of magnitude. The cost of a ResonantSonic drill rig is only an estimate but the capital cost is a small contributor, approximately $5 \%$ of the cost per foot for monitoring wells.

\begin{tabular}{|l|c|c|c|}
\hline Capital Costs & ResonantSonic Drilling & Cable-Tool Drilling & Mud-Rotary Drilling \\
\hline $\begin{array}{l}\text { Drill Rig } \\
\text { Equipment Cost }\end{array}$ & $\$ 400,000$ & $\$ 200,000$ & $\$ 450,000$ \\
\hline
\end{tabular}

The operational and maintenance costs for the three systems are comparable on a per-hour basis. The variance begins to be evident at a price-per-foot cost because of the speed at which ResonantSonic and mud-rotary drilling can proceed. ResonantSonic drilling is slower than mud-rotary but does not generate significant quantities of waste to be disposed of when working in a contaminated environment. 
Cost comparison Sonic/Cable-tool/Mud-rotary

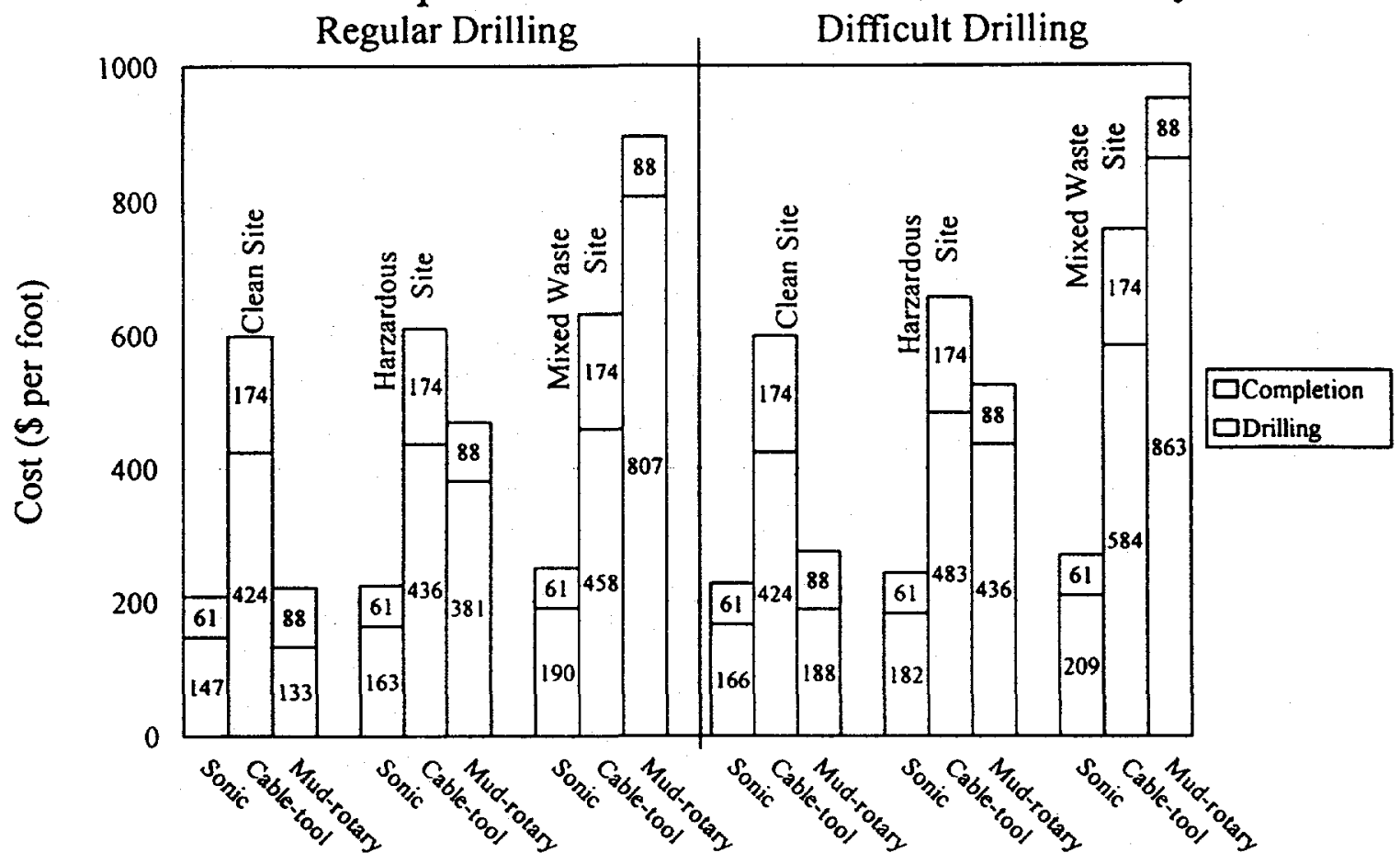

\section{Cost Results}

-The demonstrations at Sandia show that the technology may begin to compete with mud-rotary drilling at clean sites.

-At contaminated sites, ResonantSonic drilling is clearly more cost effective.

-1994 drilling at Hanford showed lower costs.

- 3 holes were drilled to an average depth of 309 feet, 11 -inch diameter.

- 2 of these holes were completed as 4-inch wells and 1 was completed as a 3-inch piezometer.

- Drilling costs were $\$ 194$ per foot; costs including a field sampling team were $\$ 253$ per foot.

-Recent drilling at Hanford to install shallow 3-inch piezometers has been accomplished for as little as $\$ 30$ per foot.

-Additional cost information using the new drilling equipment is needed to validate the cost effectiveness of the ResonantSonic lechnology. Prudence should be exercised in using the 1991-1992 cost data. 


\section{SECTION 6}

\section{REGULATORY/POLICY ISSUES}

\section{Regulatory Considerations}

-The ResonantSonic drilling technology requires all of the normal permits associated with other drilling technologies. No special permits should be required.

- The Hanford demonstration did not require NEPA review because the testing was part of the site characterization activities for the Expedited Response Action (ERA), meeting the requirements for a categorical exclusion. Drilling at many of the DOE federal sites, such as the Savannah River Site, is considered under NEPA to be a categorical exclusion.

-Wells must be constructed according to state standards but should not present any difficulties over other drilling methods.

- Normal drilling activities require that investigative-derived wastes (drilling fluids, cuttings, and equipment decontamination fluids) be handled according to RCRA.

-OSHA requirements must be reviewed because ResonantSonic drilling, like all drilling methods, produces noise levels that are considered dangerous to workers not wearing proper protection. New style heads have significantly reduced noice levels.

\section{Regulatory Advantages}

-The ResonantSonic drilling technology has a regulatory advantage over the mud rotary technique, and to a lesser extent cable-tool technique, in that it does not require any addition of fluids to the well. Some states do not allow the addition of material into the ground at contaminated sites. ResonantSonic drilling permits installation of wells under these restrictions.

\section{Safety, Risks, Benefits, and Community Reaction}

\section{Worker Safety}

- Health and Safety issues for the installation and operation of ResonantSonic drilling are essentially equivalent to those for conventional drilling technologies. Worker exposure to hazardous and radioactive materials will be less because drilling fluids are not used and cuttings are not generated.

- Level D personnel protection was used during the operation of the ResonantSonic drilling system.

\section{Community Safety}

- ResonantSonic drilling does not produce routine release of contaminants.

- No unusual or significant safety concerns are associated with transport of equipment samples, waste, or other materials associated with ResonantSonic drilling.

\section{Environmental Impacts}

- ResonantSonic drilling systems require relatively little space similar to other drilling systems.

- Visual impacts are minor, but operation of the drill rig create moderate noise in the immediate vicinity.

\section{Socioeconomic impacts and Community Perception}

- ResonantSonic drilling has a minimal economic or labor force impact.

- The general public has limited familiarity with ResonantSonic drilling. 


\section{LESSONS LEARNED}

\section{Implementation Considerations}

- When considering the selection of ResonantSonic at a particular site, the ResonantSonic drilling technology must be compared with other drilling technologies and evaluated on the basis of specific site needs and conditions.

- At Hanford it has been compared with the baseline cable tool technology, and at Sandia it has been compared with a baseline mud rotary system (see cost section).

- Waste minimization is a significant feature of sonic drilling.

- At Hanford sites characterized as not difficult, ResonantSonic drilling generated about the same amount of waste as the cable tool system, whereas under difficult drilling conditions sonic generated approximately one-fourth the amount of waste.

- Comparison of ResonantSonic drilling to mud rotary shows significant minimization of waste using the sonic method.

- Heating of core materials to be sampled for volatile chemical contaminants remains an issue for drilling technologies where no fluid is used to cool the formation, especially under difficult drilling conditions.

- Both ResonantSonic and cable tool have been shown to generate core temperatures from 70 to 140 degrees Fahrenheit under difficult drilling conditions at Hanford.

- Hollow-stem augering has been demonstrated to increase core temperatures to 107 degrees Fahrenheit, but temperatures average 76 degrees.

- New techniques to minimize temperature elevations in core materials have been developed, demonstrated, and should be implemented when collecting core samples for chemical analyses of volatile components (see Section 4, Hanford CRADA).

\section{Technology Limitations/Needs for Future Development}

- Richterich (1994) noted that "further study of factors such as lithology, penetration rates, amount of vibration, rotation, etc. should be studied to improve the quality of the core runs."

- Few drilling companies can provide ResonantSonic drilling services. Thus, the costs of mobilization may preclude the cost effective use of the technology, especially when only a few boreholes are required to complete a job.

- Further demonstration and implementation of the Sandia National Laboratory dynamics monitoring system should be completed so that imminent drill pipe failures can be predicted in real-time and coordinated with a system shutdown. In addition, improved understanding of the dynamics of ResonantSonic drilling will ultimately lead to further improvements in tool-joint design.

- Needs include design and manufacture of different-sized drilling rigs so that the right system can be used for the job, optimizing costs incurred.

- Work is under way to combine the ResonantSonic technology with push technology such as the cone penetrometer to assist with penetration of thin, hard layers. Development of this new system will create a new niche that will enhance the drilling toolbox.

\section{Technology Selection Considerations}

- Development, manufacture, and implementation of drilling systems with capabilities of multiple technologies will likely provide the lowest costhighest quality methodology under difficult driling conditions.

- Using the WDC new driling rig, wells at Hanford were installed using the ResonantSonic Casing Drive Method in the unsaturated zone and the ResonantSonic dry core method conbined with cable-tool hole-cleanout technology below the water table.

- Many sites will benefit from the application of push technology for small-diameter and shallower holes. However, a relatively large percentage of sites will require innovative drilling technology such as sonic.

- Specific job requirements and site conditions will dictate the application of the best drilling technology or combination of technologies at a particular site. Innovative technologies, such as ResonantSonic drilling, should be considered within the toolbox of available technologies. 


\section{APPENDIX A}

\section{DEMONSTRATION SITE CHARACTERISTICS}

- Field demonstrations of the sonic drilling technology described in this report were conducted at both the DOE Hanford Site and Sandia National Laboratory.

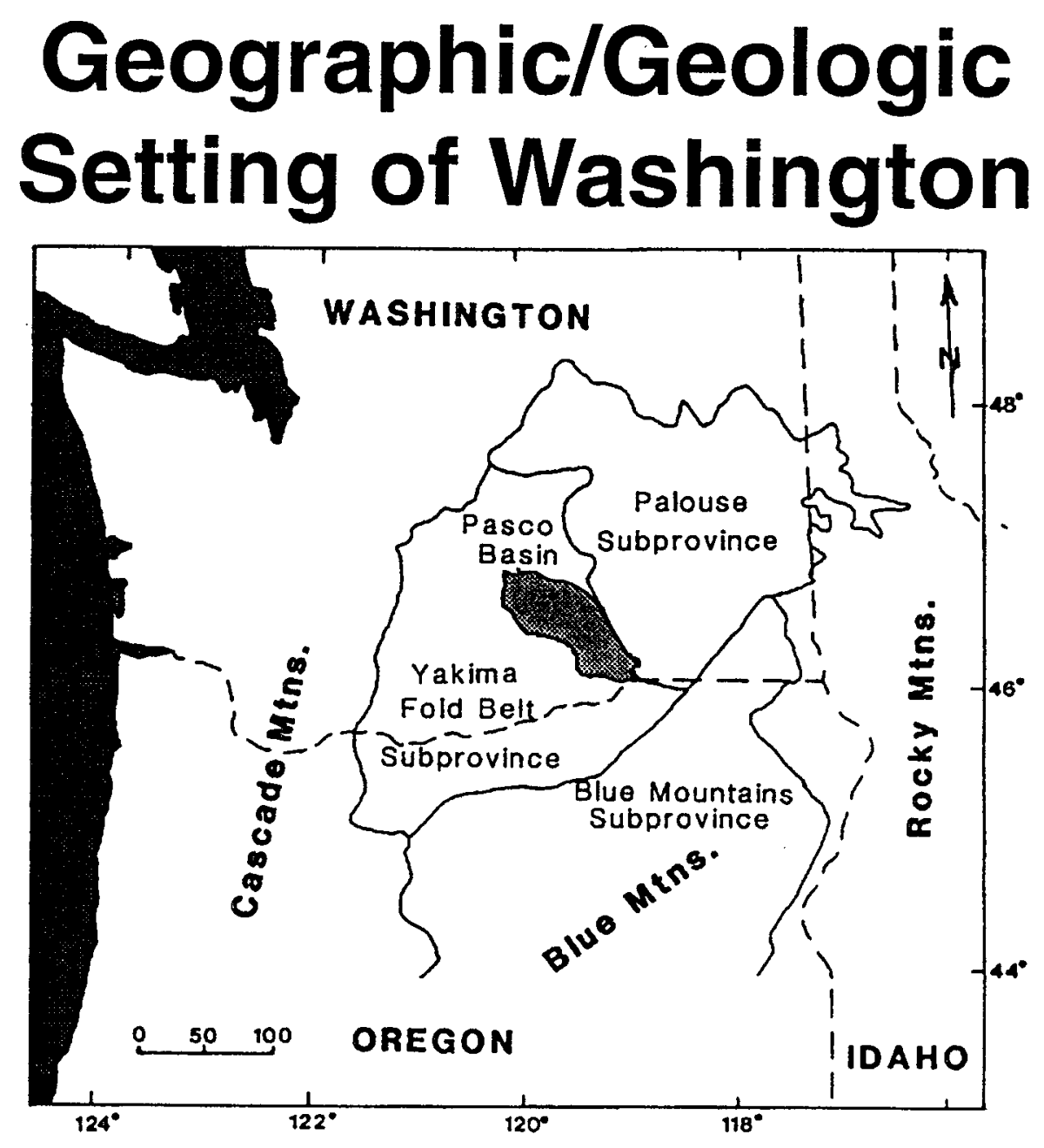


Most of the drilling for the ResonantSonic demonstrations occurred within the Hanford Formation, which contains two facies:

(1) a coarse-grained sand and granule-to-boulder gravel from which matrix is commonly lacking, and

(2) fine- to-coarse-grained sand and silt that commonly display normally graded mythmites a few centimeters to several decimeters thick. In general, the coarse facies is composed of approximately 50 percent sand and gravel, 45 percent cobble, and five percent boulder, and ranges in thickness from 20 feet to greater than 200 feet. The underlying fine facies consists of 5 to 60 feet of silts and fine sands, which in turn are underlain by Plio-Pleistocene Palouse soils, which consist of eolian silts and clay overlying a caliche layer of cemented silt, sand, and gravel.

\section{Geographic Setting of Hanford Site}

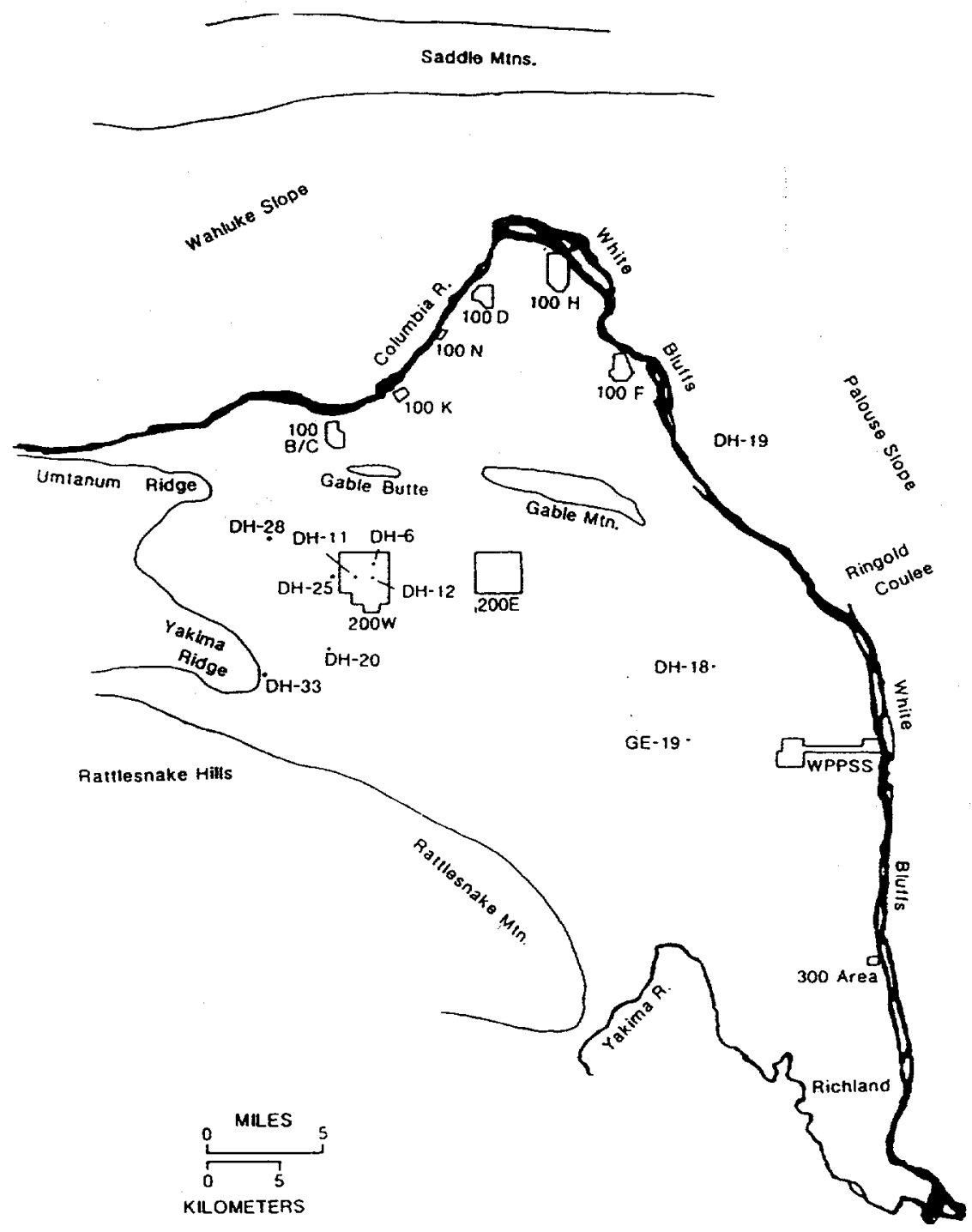




\section{Generalized Stratigraphy of the Suprabasalt Sediments at the Hanford Site}

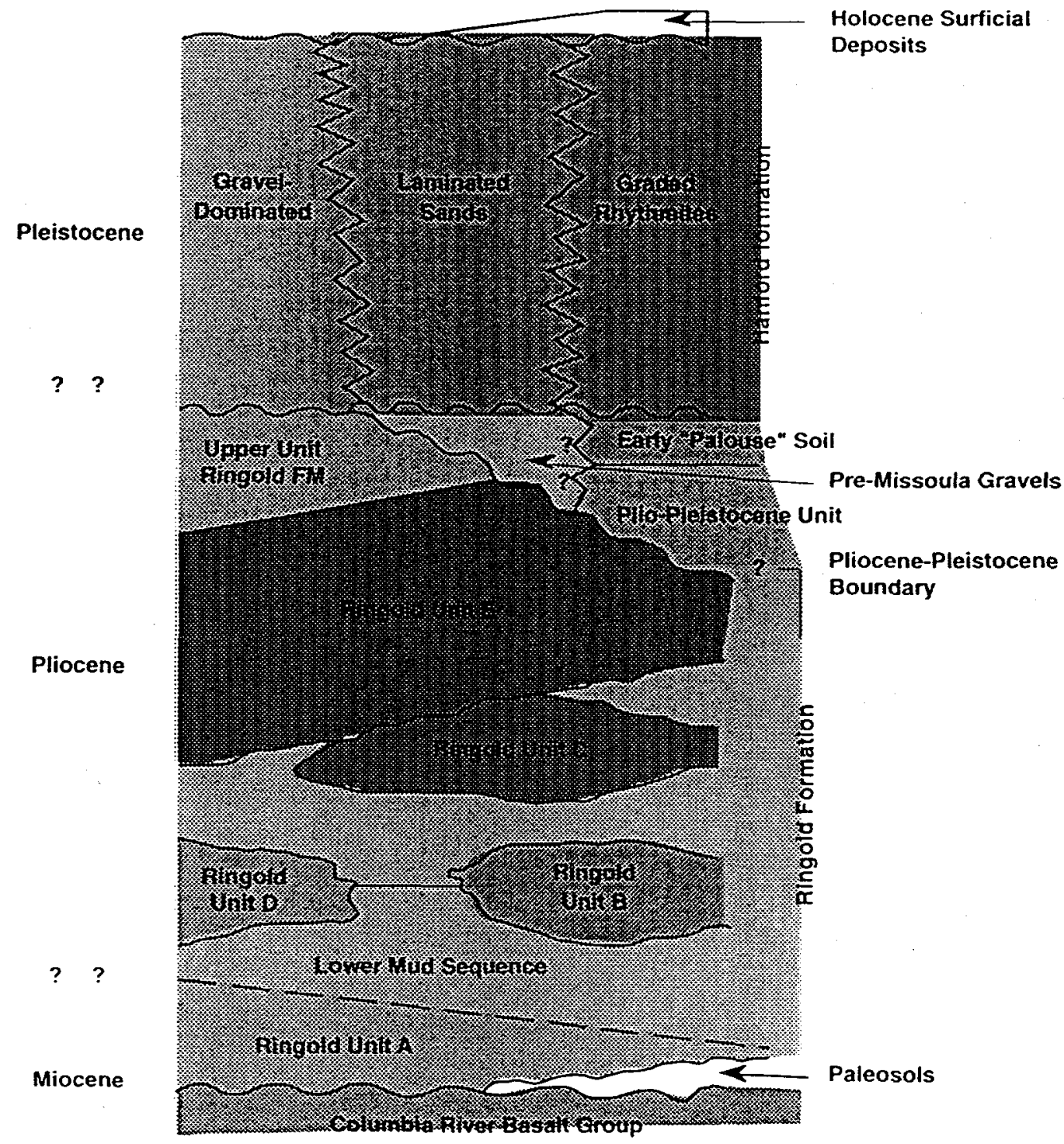


- Below the Palouse soils is about 20 feet of fluvial sands and muds underlain by relatively well compacted fluvial gravels, all of the Ringold Formation.

- Most of the demonstration work was conducted in the 200 Areas of Hanford where the depth to the water table is approximately 200 feet.

- The DOE Hanford Site is located in south central Washington State. The Sandia National Laboratory, at Kirtland Air Force Base in Albuquerque, New Mexico, is located near the east-central edge of the Albuquerque Basin, one of a series of north-south trending basins that make up the Rio Grande rift zone. The basin edges are bounded by uplifted fault blocks. The Albuquerque Basin is presently filled with up to 12,000 feet of Miocene and Pliocene sediments that were eroded from the surrounding highlands. This sequence of sediments, called the Santa Fe Group, consists of basin-fill alluvial fan materials, with channel deposits, debris flows, floodplain deposits, and eolian deposits. The Santa Fe Group sediments are overlain in places by Pliocene Ortiz gravels and Rio Grande River fluvial deposits, interbedded with Tertiary and Quaternary basalts and pyroclastics. -The sediments are extremely heterogeneous, complexly interlayered units consisting of sands, gravels, and cobbly

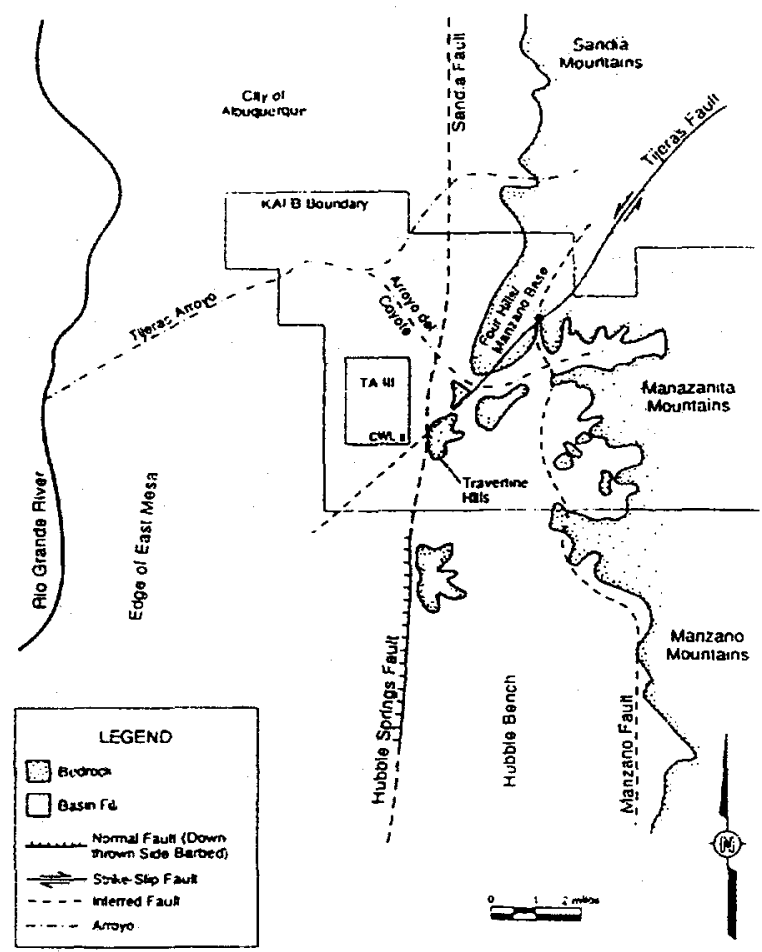

Lewation Map of CWL. units. Discontinuous low-permeability layers are present as clay-rich or caliche-cemented zones.

-The water table underlying the site is approximately 500 feet below the surface.

-Wells have been drilled at the site using mud rotary, augers, and air rotary casing hammer techniques.

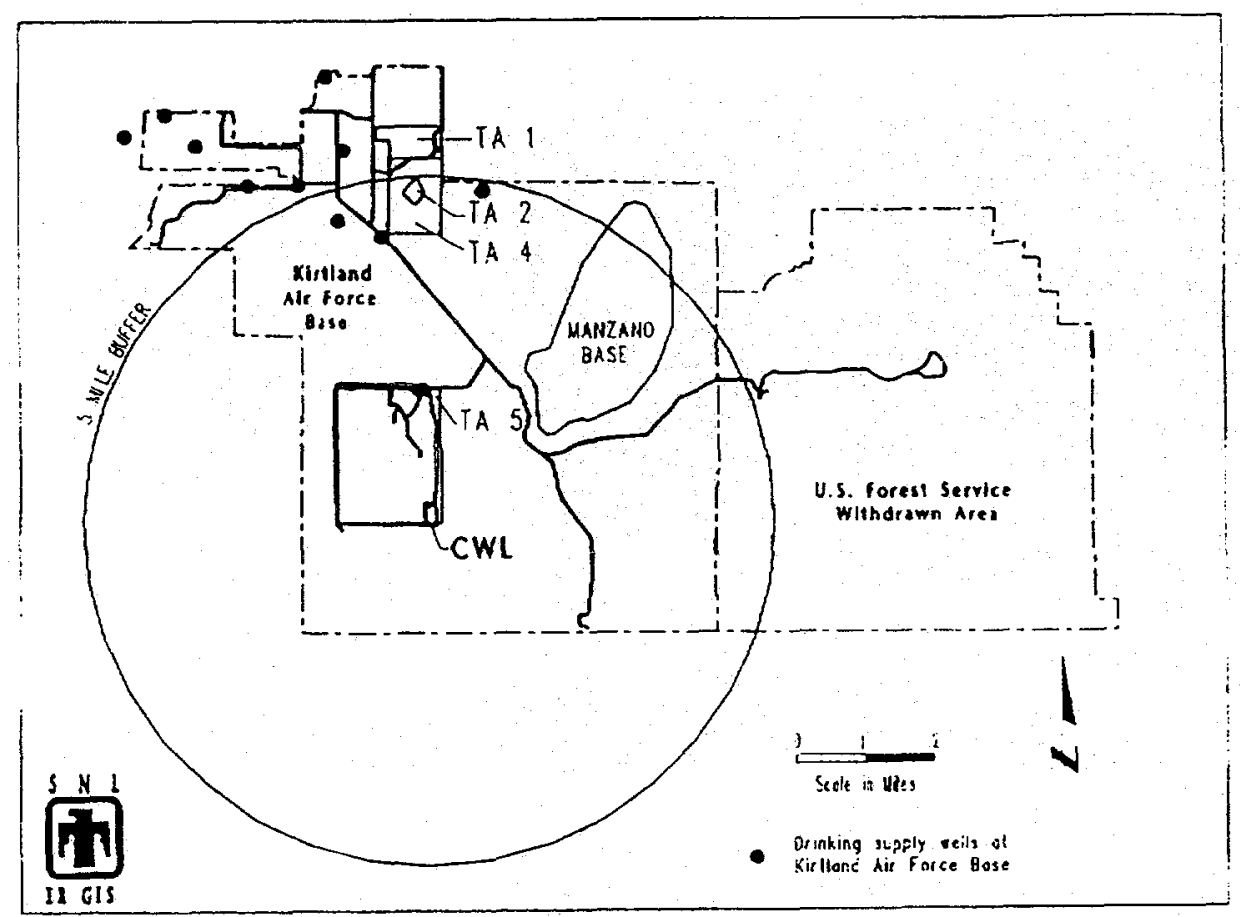




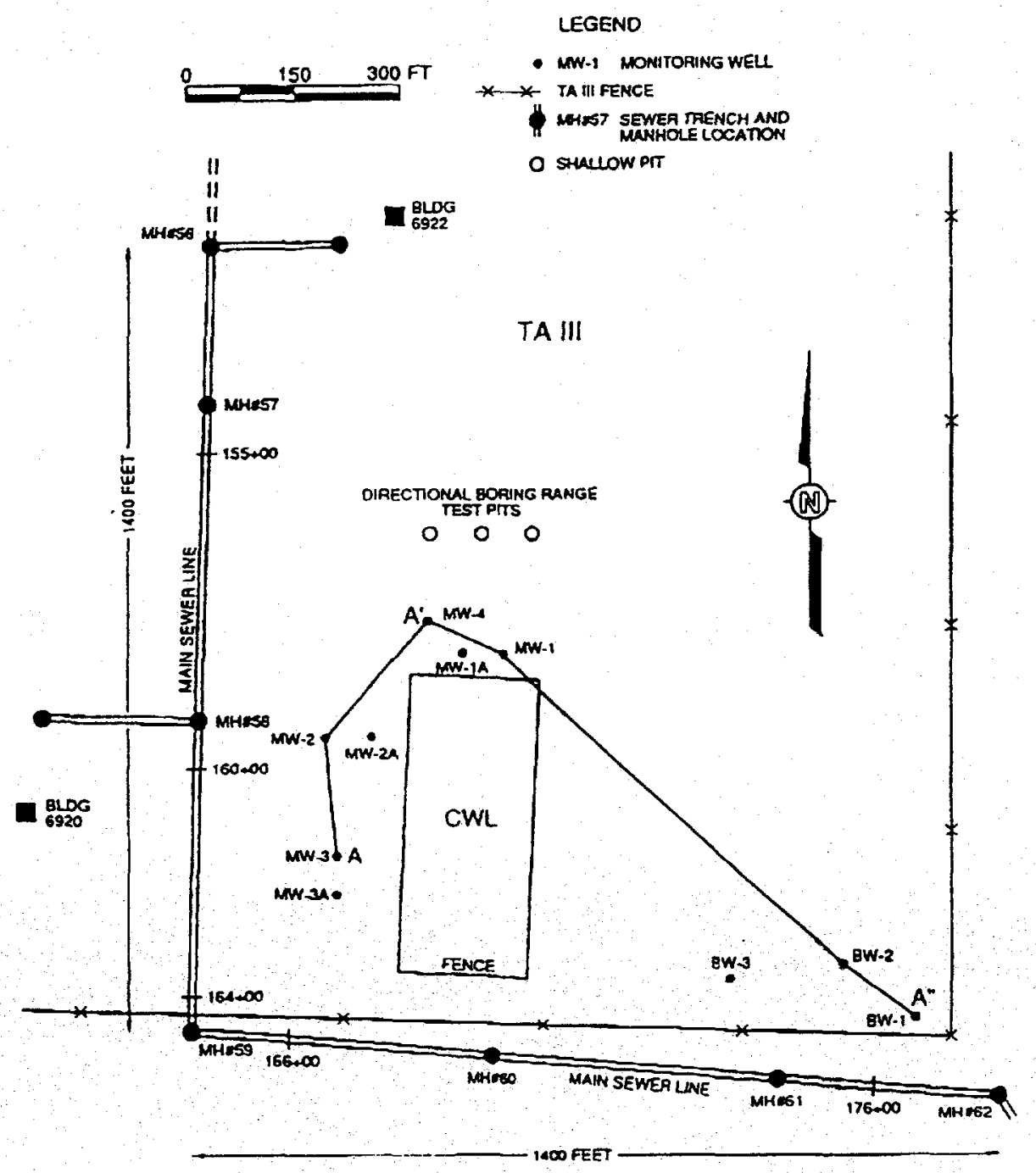

Generalized Geology and CWL Map Showing Location of Geologic Cross Sections 


\section{APPENDIX B}

\section{REFERENCES}

1. Volk, B. W., 1992, Results of Testing the Sonic Drilling System at the Hanford Site (September 1991 to May 1992), WHC-SDEN-TRP-002.

2. Volk, B.W., D.J. Moak, J.C. Barrow, K.M. Thompson, G.W. McLellan, R.E. Lerch, 1993, ResonantSonic Drilling: History, Progress and Advances in Environmental Restoration Programs, WHC-SA-1949-FP.

3. Richterich, L.R., 1994, Phase I Resonant Sonic CRADA Report, WHC-SD-EN-TRP-007.

4. Masten, Dave and Steven Booth, 1995, Cost-Effectivenss Study of Sonic Drilling, Los Alamos National Laboratory Report, preprint.

5. Barrow, Jeffrey, 1994, The ResonantSonic Drilling Method, Ground Water Monitoring and Remediation, Spring 1994, V.XIV, No. 2., p. $153-160$.

6. Wise, Jack, 1994, Arid Sonic Drilling, Sandia National Laboratory TTP AL2-3-10-05.

7. Volk, B.W., G.W.McLellan, and B.R. Cassem, 1993, Sonic Drilling System Technology Demonstration Conceptual Test Plan 1993, Westinghouse Hanford Company.

8. Barrow, Jeffrey, 1995, Water Development Corporation, personal communication.

9. McLellan, Greg, 1995, Westinghouse Hanford Company, personal communication.

10. Wise, Jack, 1995, Sandia National Laboratories, personal communication.

11. Phelan, Jim, 1995, Sandia National Laboratories, personal communication.

12. Booth, Steven, 1995 , Los Alamos National Laboratory, personal communication. 
This report was prepared by:

\section{Colorado Center}

for

Environmental Management

999 18th Street, Suite 2750

Denver, Colorado 80202

Contact: Dawn Kaback

(303)297-0180 Ext. 111

in conjunction with:

\section{Hazardous Waste Remedial Actions Program \\ Martin Marietta Energy Systems}

P.O. Box 2003

Oak Ridge, Tennessee 37831-7606

Randall Snipes/Scott Colburn

(615)435-3128/(615)435-3470

Assistance was provided by the

Westinghouse Hanford Company

and

Water Development Corporation 